\title{
MOLUSKA PADA HYDROID (Aglaophenia cupressina) DI PERAIRAN BARAT PULAU SILADEN MANADO SULAWESI UTARA
}

\author{
Alex Denny Kambey \\ Program Studi Manajemen Sumberdaya Perairan, \\ Fakultas Perikanan dan IImu Kelautan Universitas Sam Ratulangi Manado
}

\begin{abstract}
Mollusks are one of benthic organisms that live on the sea bottom, often on the roots, stems, and leaves of plants. Hydroids (Aglaophenia cupressina), one constitueht of coral reef organisms in the waters of Siladen Island, Manado, North Sulawesi, which is also an organism that has stingy nematocysts for divers in the region where they live, is a habitat of mollusks. Hydroids sampling was done by Scuba diving at 5 different depths, reef-flat, $5 \mathrm{~m}, 10 \mathrm{~m}, 15 \mathrm{~m}$, and $20 \mathrm{~m}$, respectively. Ath mollusks specimens were taken to the laboratory for species identification. Results found three species of epibiont mollusks on the hydroids, in which the bigger the hydroid size the larger the volume, and higher number was found. This results from that the mollusks use the hydroids as a shelter from predator attacks, strong currents, and waves, and food search.
\end{abstract}

Key words: Ecosystems, Coral Reefs, Mollusks, Ephibiont

\section{PENDAHULUAN}

Hydrozoa ditemukan sekitar 3.000 spesies yang hidup, dan dalam siklus hidupnya, kelas ini mengalami tahap polip, dan medusa (Kozloff, 1990), terbagi atas sub-ordo Thecate (Leptomedusae)d Athecate (Anthomedusae), Limnomedusae, Milleporina, Stylasterina, Trachylina, Siphonophora, dan Actinulida. Penyebarannya dari daerah perairan dangkal sampai kedalaman 30-40 m, dan haßini menyebabkan banyak penelitian dilakukaan pada kedalaman 5-15 m (Watson, 2002). Hewan ini hidup sebagai hewan yang berenang bebas maupun menempel pada substrat keras, seperti batu-batuaa, tiang-tiang pelabuhan, dan pasir (Sohuchert, 2003). Hewan ini menyebar dari daerah tropis sampai subtropis (Kozlof 1990). Penelitian tentang penamaan hydroid telah dilakukan sejak awal abad ke 19, dimana dalam expedisi Danish tahun 1922 di Kepulauan Kei, Indonesia. Beberapa nama hydroid dari perairan Maluku telah diberikan oleh Pieter dan Bedot, 1890 yang telah direvisi (Schuchert, 2003). Sejak awal abad ke 20, terdapat 15 spesies hydroid tercatat dari perairan Indonesia oleh Hirihito (1988), Nutting (1905), Pennycuik (1959), Watson (1985), Kirkpatrick (1890), Inaba (1892), Sars (1874), Jarvis (1922),
Bale $(1884,1914)$, Fleming (1820), Hargitt (1924) dan (Mulder \& Trebilcock, 1909).

Aglaophenia cupressina Lamouroux, 1816 (Hydroid, Leptomedusae) adalah salah satu dari sekian banyak spesies hydroid yang terdapat di Indonesia lebih khusus terdapat di perairan pantai. Perairan Pulau Siladen merupakan salah satu bagian dari wilayah Taman Nasional Bunaken, memiliki beranekaragam organisme dari jenis-jenis invertebrata terutama ekosistem terumbu karang dan jenis vertebrata seperti ikan, organisme ini (hydroid, Leptomedusa) juga merupakan salah organisme penyusun terumbu karang.

Bentuk pertumbuhan polip bercabang-cabang seperti tumbuhan dan terdapat kandungan nematocyst pada hampir seluruh bagian tubuh hydroid Aglaophenia cupressina, dimana sentuhan manusia akan membuat terasa sangat menyengat, sehingga perlu untuk diketahui apakah ada organisme lain yang dapat hidup pada tubuh dari organisme ini atau yang berasosiasi dengannya, juga memanfaatkan tubuh organisme ini sebagai tempat berlindung dan kepentingan lainnya.

Hal ini menjadi suatu dasar untuk dilakukan penelitian untuk memperoleh informasi tentang Aglaophenia cupressina dan organisme yang berassosiasi, terutama untuk jenis-jenis organisme benthos seperti 
moluska yang disebut juga epibiont terhadap hydroid.

Pada daerah terumbu karang umumnya dijumpai moluska, seperti Gastropoda dan Bivalve (Litaay, 1994; Latama dan Nessa, 1994). Moluska tergolong biota yang memiliki keanekaragaman spesies tinggi dan menyebar luas di berbagai habitat laut, mulai dari zona supratidal hingga laut dalam. Dharma (1988 dan 1991) menyatakan bahwa moluska banyak menempati daerah terumbu karang, berasosiasi dengan karang dan menjadikan terumbu karang sebagai tempat hidup.

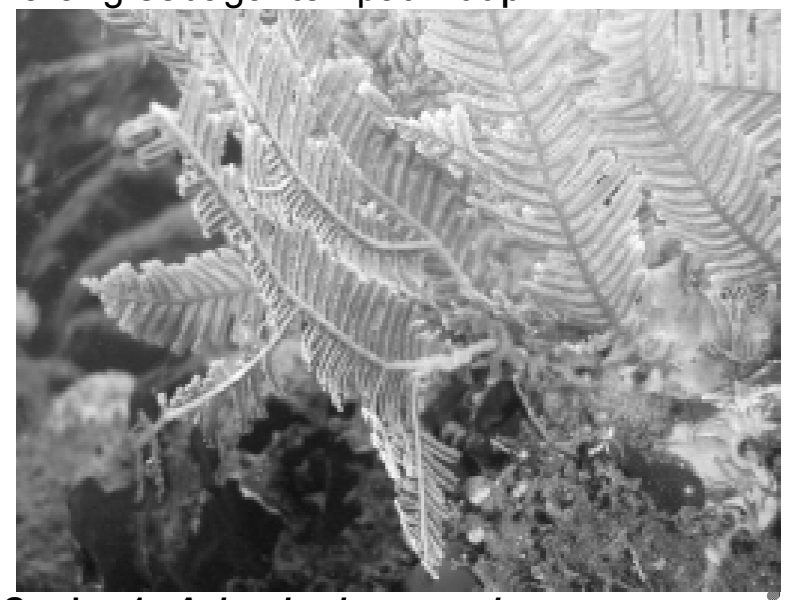

Gambar 1. Aglaophenia cupressina.

\section{METODOLOGI PENELITIAN}

Sampel hydroid diperoleh dari perairan pantai pulau Siladen sebelah Barat dengan menggunakan SCUBA, dan dilakukan sampai pada kedalaman 20 meter. Sebanyak 15 koloni Aglaóphenia cupressina diambil, masing-masing 3 koloni untuk tiap kedalaman yaitu daerah rataan, 5, 10, 15 dan 20 meter. Setjap koloni diambil menggunakan kantóng plastik yang telah diberi tanda untuk tiap kedalaman, kemudian dengan cara menutupi dari bagian atas sampai mencapai bagian substrat dari koloni $A$. cupressina dan memotong pada bagian akarnya, kemudian kantong diikat dengan karet yang juga telah diberi nomor pengambilan sampel. Menghindari terjadinya kerusakan atau membusuknya sampel tersebut, maka dilakukan pengawetan menggunakan larutan formalin $4 \%$. Sampel dibawa ke laboratorium untuk dilakukan pengamatan atau analisis terhadap organisme yang ada pada tiap koloni hydroid. Sebelum pengamatan tersebut, dilakukan penyaringan terhadap air yang ada di dalam kantong untuk memisahkan air dan organisme menggunakan plankton net berukuran $40 \mu \mathrm{m}$, untuk melihat jenis-jenis moluska.

Tabel 1. Kepadatan moluska berdasarkan kedalaman perairan.

\begin{tabular}{|c|c|c|c|c|c|c|c|c|c|c|c|c|c|c|c|}
\hline & & Rf & & & $5 \mathrm{~m}$ & & $10 \mathrm{~m}$ & & & $15 \mathrm{~m}$ & & $20 n$ & & & $\Sigma$ \\
\hline Nudibranch & - & 5 & 4 & - & 14 & 5 & 10 & 5 & 1 & - & 1 & 2 & - & - & 47 \\
\hline Bivalve & 12 & 5 & 7 & 5 & 4 & 2 & 15 & 5 & 4 & 18 & 5 & 3 & 1 & 4 & 90 \\
\hline Gasteropoda & 1 & 16 & - & 3 & - & 2 & 2 & 7 & 4 & 2 & - & 4 & 3 & 6 & 50 \\
\hline Jumlah & 13 & 26 & 11 & 8 & 18 & 9 & 27 & 17 & 9 & 20 & 6 & 9 & 4 & 10 & 187 \\
\hline Total & & 50 & & & 26 & & 53 & & & 35 & & & 23 & & \\
\hline
\end{tabular}

Identifikasi moluska dilakukan mënggunakan mikroskop dissecting, kemudian dilakukan pemotretan untuk memudahkan proses identifikasi. Di samping menghitung jumlah dan jenis moluska yang terdapat pada Aglaophenia cupressina, juga dilakukan pengukuran terhado limggi, volume dan persentasi luas teturan hydroid. Adapun analisis data dilakukan dengan membuat grafik berdasárkân kepadatan pada tiap kedalaman baik untuk jumlah dan jenis moluska, maupun pada tinggi dan volume hydroid

\section{HASIL DAN PEMBAHASAN}

Perairan pulau Siladen bagian barat yang dijadikan tempat dilakukan penelitian, memiliki arus perairan yang cukup kuat, dengan dasar perairan yang terdiri dari pasir, pecahan karang mati, juga terdiri dari komunitas karang hidup. Hasil pengamatan menunjukkan bahwa struktur komunitas dasar perairan di wilayah tersebut didominasi oleh Brancing coral dan Massive coral (Runtukahu, 2005). Adapun bentuk dasar perairan di lokasi pengamatan menunjukkan adanya kemiringan sampai pada kedalaman antara 5-10 $\mathrm{m}$ dan selanjutnya merupakan daerah terjal dan secara visual dapat digambarkan berdasarkan bentuk morfologi dasar perairan seperti Gambar 2. Kehadiran Aglaophenia cupressina di daerah ini jelas adalah sebagai bagian dari organisme yang merupakan penyusun komunitas terumbu karang.

Hasil pengamatan yang dilakukan terhadap organisme Moluska yang hidup berasosiasi dengan hydroid Aglaophenia cupressina atau menempel pada koloni hydroid terdiri dari klas gastropoda, bivalve dan nudibranch. 


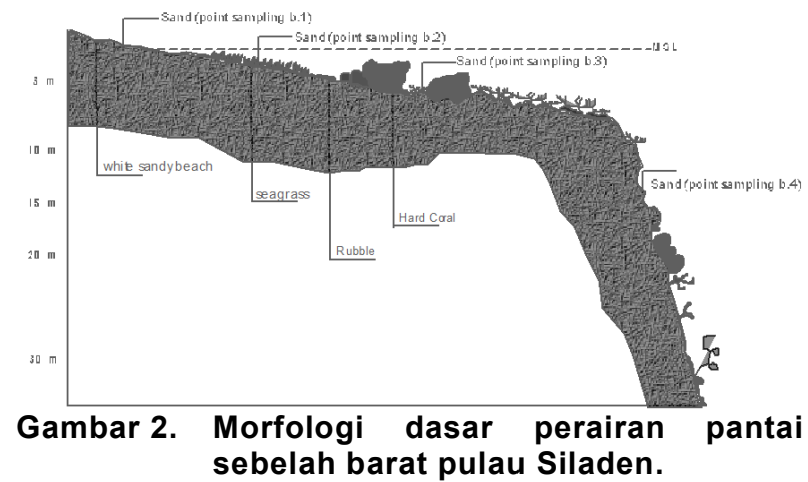

Pengamatan yang dilakukan pada sampel Aglaophenia cupressina terhadap nilai rata-rata tinggi, volume dan persentase tutupan (Tabel 2) menunjukkan bahwa untuk ukuran tinggi hydroid terbesar terdapat pada daerah reef flat dan terendah terdapat pada kedalaman $20 \mathrm{~m}$. Untuk volume hydroid yang diperoleh dengan menggunakan tehnik pengukuran volumetrik, menunjukkan terbesar terdapat pada daerah reef flat dan terendah terdapat pada kedalaman $15 \mathrm{~m}$. Kemudian untuk persentase tutupan, diperoleh nilai tertinggi pada reef flat dan terendah pada kedalaman 20 $\mathrm{m}$, dimana semakin dalam perairan semakin kecil persentase tutupan.

Tabel 2. hydroid (Aglaophenia cupressina) perairan barat pulau Siladen.

\begin{tabular}{lllllll}
\hline & $\begin{array}{c}\text { Reef } \\
\text { Flat }\end{array}$ & $\mathbf{5} \mathbf{~ m}$ & $\mathbf{1 0} \mathbf{~ m}$ & $\mathbf{1 5} \mathbf{~ m}$ & $\mathbf{2 0} \mathbf{~ m}$ \\
\hline $\begin{array}{l}\text { Tinggi } \\
\text { hydroid }\end{array}$ & 37,67 & 27,33 & 33,33 & 25,66 & 22,33 \\
$\begin{array}{l}\text { Volume } \\
\text { hydroid }\end{array}$ & 46,33 & 28,53 & 40,20 & 16,20 & 19,80 \\
$\begin{array}{l}\text { Luas } \\
\text { tutupan }\end{array}$ & 30,00 & 30,00 & 2 & & 5,00 & 2,00 \\
\hline
\end{tabular}

Analisis dafam bentuk grafik menunjukkan kecenderungăn adanya hubungan antara parameter-parameter tersebut dengan kedalaman perairan, maka semakin dalam perairan tersebut, semakin kecil ukuran baik volume, tinggi, ataupun perseptase tutupan dari Aglaophenia cupressina. Berdasarkan kedalaman perairan, diperoleh bahwa daerah reef flat dan 10 meter merupakan tempat yang nilai tinggi dan volume hydroid cukup menonjol, pada reef flat terjadi akibat pengaruh intensetas cahaya matahari sangat menonjol, demikian juga pada daerah kedalaman 10 meter yang merupakan daerah perbatasan antara daerah slope dan daerah drop off sehingga pengaruh faktor intensitas mata- hari lebih luas. Hal yang sama juga terjadi pada jumlah organisme moluska yang epibiont terhadap hydroid dimana semakin besar nilai tinggi dan volume hydroid, semakin padat kehadiran moluska. Hal ini ditunjukkan oleh kepadatan kelas bivalvia dan gastropoda yang lebih menonjol pada dua daerah tersebut.

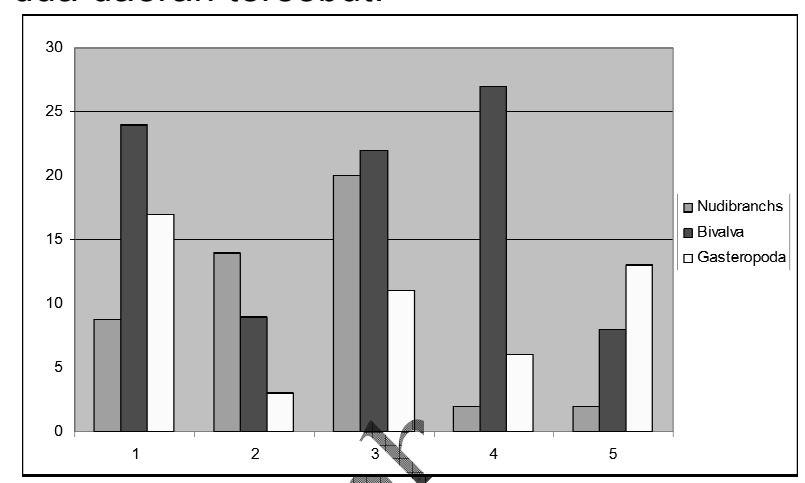

Gambar 3. Grafik júmlah moluska berdasarkan kedalaman.

$$
\text { KESIMPULAN }
$$

Kehádiran moluska pada koloni hydroid (Aglaophenia cupressina) merupakan tempat berlindung terhadap serangan predator serta hempasan arus dan gelombang perairan pantai bagian barat pulau Siladen yang cukup kuat.

Semakin besar ukuran (tinggi dan volume) hydroid (Aglaophenia cupressina) semakin banyak kehadiran moluska, yang juga dapat disebutkan sebagai pengaruh persaingan ruang dan makanan dengan organisme bentik lainnya.

\section{DAFTAR PUSTAKA}

Bale, W. M., 1884. Catalogue of the Australian Hydroid Zoophytes. Australian Catalogue No. 8; 198 hal.

Bale, W. M., 1914. Report on the Hydroida collected in the Great Australian Bight and other localities. Biological Results of Fishing Experiment carried out by the $F$. I. S. "Endeavor" 1909, 1914 2:1-62; 2:1 168-188.

Bradshaw, C., Collins, P., \& Brand, A. R., 2003. To What extent does upright sessile epifauna affect benthic biodiversity and community composition. Marine Biology. Dept. of Systems Ecology, Stockholm University. Sweden. 
Bavestrello, G., C. Cerrano., R. Cattaneovietti., \& M. Sara, 1996. Relations between Eudendrium glomeratum (Cnidaria, Hydromedusae) and its assiciated vagile fauna. Vagile fauna of Eudendrium Colonies. Instituto di Zoologia dell' Universita di Genova. Via Balbi 5 I16126 Genova.

Bengen, D. G., 2001. Sinopsis Ekosistim dan Sumberdaya Alam Pesisir dan Laut. Pusat Kajian Sumberdaya Pesisir dan Lautan IPB. Bogor.

Dharma, B 1988. siput dan Kerang Indonesia (Indonesian Shells). PT. sarana Graha Jakarta. 111 halaman.

Dharma, B 1991. siput dan Kerang Indonesia (Indonesian Shells II). Verlag Christa Hemmen Publ. 135 halaman.

Fleming, J., 1820. observations on the Natural History of Sernilaria gelatinosa of Pallas. Eidenburg Phylosophycal Journal 2:82-89.

Hargitt, C. W., 1924. Hydroid of the Philippine Islands. Philippine Journal of science 24:467-507.

Hirohito, Emperor of Japan, 1988. The Hydroids of Sagami Bay collected by $\mathrm{His}^{\circ}$ Mayesty the Emperor of Japan. Biological Laboratory of the Imperial Household Tokyo. Hal 1-179.

Inaba, M., 1892. The Hydroid collected at Mizaki, Miura, Soshur Zoological Magazine 4:93-101, 124,131.

Jarvis, F. F., 1922. The Hydroid from the Chagos, Scychelles, and other island and from the coast of British East Africa and Zansibar. Transaction of the Linnean Society of London, Zoology 18:331-360.

Kozloff, E. N., 1990. Invertebrates. Sounders College Publ. Philadelphia. 866 hal.

Kirkpatrick, R., 1890, Reporton the collections made in Torres Straits by Prof. A. C. Haddon, 1888-1889, Hydroida and Polyzoa. Proceedings of the Royal Dublin Soc. 6:603-626.

Krebs, C. J., 1989, Ecological Methodology. Harer and Row, New York. 654 hal.

Latama, G dan M.N. Nessa, 1994. Gastropods Distribution and Abundance around Kondingkareang Keke, Souuth Sulawesi, Indonesia. Phuket. Mar. Boil. Cent. Spec. Pub1.No. 133: 163-165.

Litaay. M., 1994. gastropoda Encountered on a Reef Flat at Samalona Island, south West Sulawesi, Indonesia. Phuket. Mar. Boil. Cent. Spec. Publ. No. 133: 157158

Luidwig, J. A. \& J. F. Reynolds, 1988. Statistical Ecology: a Primer on Methods and Computing. A Wiley Intercience Publication John and Son, Inc. Canada. 337 hal.

Mulder, J. F. \& R. F. Trebilcock, 1909. Notes on Victorian Hydroida, with descriptions of new spesies. The Geelong naturalist 4:29-35.

Nutting, C. C., 1905. Hydroids of Hawaian Island collectedby the steamer Albatross in 1902. Buletin of the United State Fish Commission for 1903, 23:931-959. 